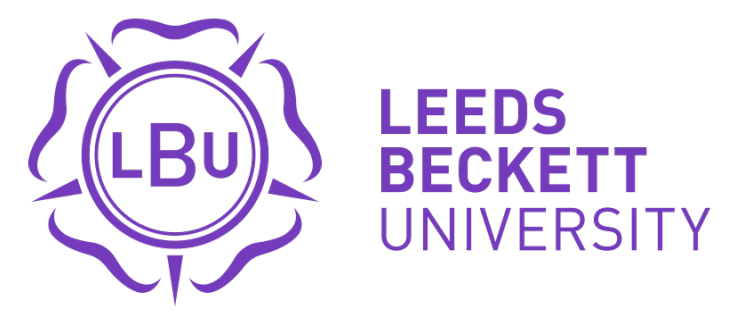

Citation:

Fylan, F and Glew, D and Smith, M and Johnston, D and Brooke-Peat, M and Miles-Shenton, D and Fletcher, M and Aloise-Young, P and Gorse, C (2016) Reflections on retrofits: Overcoming barriers to energy efficiency among the fuel poor in the United Kingdom. Energy Research and Social Science, 21. pp. 190-198. ISSN 2214-6296 DOI: https://doi.org/10.1016/j.erss.2016.08.002

Link to Leeds Beckett Repository record:

https://eprints.leedsbeckett.ac.uk/id/eprint/3013/

Document Version:

Article (Accepted Version)

The aim of the Leeds Beckett Repository is to provide open access to our research, as required by funder policies and permitted by publishers and copyright law.

The Leeds Beckett repository holds a wide range of publications, each of which has been checked for copyright and the relevant embargo period has been applied by the Research Services team.

We operate on a standard take-down policy. If you are the author or publisher of an output and you would like it removed from the repository, please contact us and we will investigate on a case-by-case basis.

Each thesis in the repository has been cleared where necessary by the author for third party copyright. If you would like a thesis to be removed from the repository or believe there is an issue with copyright, please contact us on openaccess@leedsbeckett.ac.uk and we will investigate on a case-by-case basis. 


\title{
Reflections on Retrofits: overcoming barriers to energy efficiency among the fuel poor in the United Kingdom
}

\begin{abstract}
To meet targets on fuel poverty, energy efficiency and carbon emissions existing homes need to be more energy efficient. We report the results of a participatory action research project to explore the challenges associated with energy efficiency retrofit programmes and ways to better implement future schemes.
\end{abstract}

Six focus groups were held with 48 participants from a range of energy efficiency roles. Data were analysed thematically using the research question "What are the challenges presented by implementing energy efficiency retrofit programmes".

We identified four themes in the data: Funding mechanisms; Predicting performance; Installation; and People. Challenges include funding mechanisms for retrofit programmes resulting in insufficient time to plan, publicise, implement and evaluate a scheme and insufficient flexibility to specify the most appropriate intervention for individual homes. Site workers sometimes need to adapt retrofit designs because of insufficient detail from the designer and can equate quality of installation with quality of finish. Landlords and occupier behaviour can impact on the programme's success and there is a need for greater information on benefits for landlords and for energy behaviour change interventions run alongside retrofit programmes for occupiers. There is a need for outcome evaluations of retrofit schemes with the results shared with stakeholders.

Key Words: retrofit; energy efficiency; energy policy; performance gap.

\section{Introduction}

There are several key drivers to helping households reduce the energy they consume, arising from both the need to reduce fuel poverty and to reduce carbon emissions. Living in a warm home not only means that occupants can save money but it can also lead to improvements in physical and mental health (Marmot Review Team, 2011, Cronin de Chavez, 2014). There was a legal commitment from the UK Government that, as far as practical, by 2016 there should be no households living in fuel poverty (Warm Homes and 
Energy Conservation Act, 2000). Progress to this goal has been slow, however, with around $10 \%$ of households in fuel poverty and no decrease in this figure over recent years (DECC, 2015). More recently, in the UK there is a target that all households should have an energy efficiency rating of at least C by 2030 (Fuel Poverty (England) Regulations, 2014). As well as social drivers, homes need to become more energy efficient in order to meet carbon emissions targets. The UK, alongside other European countries, is required to reduce carbon emissions by $80 \%$ before 2050 (Climate Change Act, 2008). A substantial amount of this saving will need to come from the domestic setting (Committee on Climate Change, 2008; Johnston et al., 2005; Lowe \& Oreszczyn, 2008; Preston et al., 2013; Skea, 2012; Summerfield and Lowe, 2012).

While new homes in the UK must meet energy efficiency requirements, a combination of low new build rates and low demolition rates means around $80-85 \%$ of homes occupied in 2050 are likely to be those currently standing today (Boardman, 2007; Killip, 2008). Consequently, there is a need to focus on improving the energy efficiency of existing homes (EST, 2008). In the UK there is a range of energy efficiency improvement schemes for existing homes funded under the Energy Company Obligation (Electricity and Gas (Energy Companies Obligation) Order 2012), and until recently, the Green Deal Scheme (DECC, 2013). Funding schemes also operate in Europe and in the USA, e.g. the US Department of Energy Weatherization Assistance Program (US Department of Energy, 2016). Schemes typically include conventional improvements such as upgrading boilers and installing loft insulation and cavity wall insulation. Some homes, termed "hard-to-treat", cannot accommodate conventional cost-effective fabric energy efficiency measures (EST, 2004; BRE, 2008; DCLG, 2012), primarily because of the nature their construction, for example they have solid walls, they have no loft, or they are high-rise flats (BRE, 2008). There have been various programmes to improve the energy efficiency of hard-to-treat homes, primarily focusing on internal or external wall insulation. Both local authorities and social housing associations provide such schemes, usually bearing the majority of the cost, as their tenants are generally on low incomes and are often in fuel poverty (Sunikka-Blank et al., 2012). Using these schemes to reduce fuel poverty has been criticised, however, because of the inherent tensions within the policy. The suppliers' obligation is to reduce energy consumption which means their most effective strategy is to target homes that will produce the greatest savings (Rosenow et al., 2013). However, those in fuel poverty tend to under- rather than overconsume energy, often keeping their homes at a temperature substantially less than the recommended 21/18 degrees for living room/other rooms (Public Health England, 2014). This is referred to as the pre-bound effect (Sunnika-Blank and Galvin, 2012) and it means 
that the projected energy savings cannot be met because the pre-intervention energy use is already very low. The effect could be to shift the focus of retrofit work away from low-income homes to those homes where there is a greater potential to meet carbon-saving targets.

Particularly with hard-to-treat homes, in which energy efficiency improvements are likely to be more expensive, there is a need to evaluate the effectiveness of retrofit programmes in improving energy efficiency. In recent years, the importance of evaluation has increased as it has become apparent that in existing, as well as new dwellings, there is often a considerable gap between the measured and the predicted performance of the building (Stafford, Bell \& Gorse, 2012, Galvin, 2014). This gap can be caused by problems with the design and specification stage, the construction stage, or the handover stage (Gupta et al., 2015). The design and specification stage can be affected by lack of understanding of the impact of design decisions on energy performance, limitations in the accuracy of modelling tools, and failing to take into account energy under-use in fuel-poor households (Gupta et al., 2015). The construction stage can include substituting the specified products with alternatives, and errors or violations during installation. Finally, an absent or inadequate explanation of how to operate, control and maintain their retrofit can result in occupants making inappropriate choices about energy use in their homes (Linden et al., 2006). This can be because occupants were not instructed in how to use new technology, or they are reluctant to engage with the technology (Isaksson, 2014). In some cases, the gap between predicted and measured performance can be substantial: differences of greater than $100 \%$ have been documented (Carbon Trust, 2011; Johnston, et al., 2014; Johnston, Miles-Shenton \& Farmer, 2015; Stafford, Bell \& Gorse, 2012; Zero Carbon Hub, 2010, 2014).

Previous energy efficiency programs funded by the UK government have been appraised by looking at utility bills as part of the Homes Energy Efficiency Database (HEED). These appraisals have confirmed the presence of this performance gap for almost all retrofit technologies (DECC, 2012) although this level of analysis is not able to identify why potential energy savings are not achieved. For this, and to help ensure that savings made are at least equal to the cost of installation (a rule in many retrofit schemes) a better understanding of energy efficiency performance is needed. Detailed monitoring and evaluation programs have therefore been established to investigate whether the expected increases in energy efficiency have been achieved by policies such as the Energy Company Obligation (ECO) and the Green Deal (House of Commons Energy and Climate Change Committee, 2013). The UK's Department for Energy and Climate Change (DECC) has funded several such evaluations linked to the Go Early Green Deal core cities investment programme which are currently underway and the results pending (DECC, 2013, 2014). While such evaluation 
schemes yield valuable information that helps to identify the extent and cause of the performance gap, there is also a need for process evaluations to assess how programmes and policies have been implemented from the perspective of different stakeholders and whether this has impacted on performance. This could help ensure that the right policies are implemented in the most effective way. Here we report the results of a participatory action research project in which we explore the challenges presented by implementing an energy efficiency retrofit programme, how these could relate to the performance gap, and how future retrofit schemes could be better implemented.

\section{Methods}

\subsection{Context}

We took a participatory action research approach (Walters, 2009) in which researchers, policy makers, commissioners, designers and installers working on energy efficiency explored the challenges presented by retrofit schemes. This approach engages researchers and practitioners in a collaborative process in which knowledge is co-created from participants' varied experiences. Data collection took place during an event to share preliminary findings from a UK research project to evaluate the effect of Green Deal energy efficiency improvements. The Green Deal is a UK initiative in which occupants take out a low-interest loan to pay for energy efficiency improvements. The cost of the improvements need to be less than the estimated energy savings, so that the improvements essentially pay for themselves over the duration of the loan. The evaluation project was funded by DECC and included monitoring the temperature, humidity, energy consumption and occupant experiences in 59 different homes both before and after various fabric and system interventions. While any Green Deal interventions were eligible to be included in the retrofit programme, three quarters were hard-to-treat homes which received external wall insulation $(50 \%)$ or internal wall insulation (25\%) and had been commissioned by local authorities or housing associations. The event took place in the North of England in March 2015 and comprised nine presentations on different aspects of the evaluation findings and the experiences of delivering the programme. The presentations addressed: an overview of the research project; thermal bridging and hygrothermal behaviour; air tightness; building surveys; thermal performance; energy consumption; occupant behaviour; and energy efficiency policy. The delegates were informed about the action learning project that would take place after the presentations and all opted to take part. 


\subsection{Participants}

A total of 48 participants took part. They had a range of professional roles including housing association officers, insulation manufacturers, local authority housing and policy officers, retrofit contractors, Green Deal providers, environmental designers, architects, university researchers, and Department of Energy and Climate Change project officers. Three quarters were associated with the Green Deal programme evaluated by the University. The remaining quarter were involved in delivering aspects of other retrofit programmes, at a policy, planning, design or monitoring level, or in a tenant-facing role.

\subsection{Data collection}

Six focus groups were conducted, each with eight participants and each lasting an hour. The groups comprised a mix of different professional roles so that a range of different perspectives and experiences could be discussed. While the exact composition of each group differed because of the unequal numbers of participants with different professional roles, each comprised at least one university researcher, one housing association officer, one local authority housing and policy officer and one insulation manufacturer. Four of the groups contained a Green Deal provider and an environmental designer. Three of the groups contained a Department of Energy and Climate Change project officer and a retrofit contractor. Each group was facilitated by a university participant researcher, who guided discussions around four different areas: type of intervention; fabric and services; occupants; and measurements and observations. These areas were selected on the basis of three stages of retrofit challenge described by Gupta et al. (2015) and we added the topic of measurement to encourage participants to discuss how data could help or hinder retrofits. Within each area the facilitator explored participants' experiences, the challenges that they had faced, why these challenges had arisen, and how they could be overcome. The facilitator took comprehensive field notes of participants' discussions and the challenges and solutions their group developed.

\subsection{Data analysis}

We analysed the field notes thematically according to the methods of Braun and Clarke (2006) using the research question "What are the challenges presented by implementing energy efficiency retrofit programmes". This approach is inductive so that the findings were not constrained by pre-determined categories and could provide a full account of the data collected. First of all, data relevant to the research question were coded by assigning a word or a group of words to each segment of the field notes that were relevant to the research question. These codes summarised the essence of the data segment and were grouped into 
categories of similar codes. Second, the categories were grouped together with others of similar meaning into sub-themes. The subthemes themselves were then grouped together into themes which described a particular perspective on the challenges faced by retrofit programmes. The criteria for a theme were (a) it is internally homogeneous, i.e. the subthemes it contains all share a certain feature or perspective, and (b) it is externally heterogeneous, i.e. that the themes differ from one another in a fundamental way, e.g. a different topic or a different perspective. This stage was iterative, with sub-themes merging and moving across themes, until the most parsimonious groupings that fully represented the data were identified. At every iteration, each sub-theme and the categories that comprise it were moved between themes rather than replicated, so that each of the themes and subthemes represent distinct data. Finally, quotes from the field notes were selected to illustrate the themes. Throughout the data analysis process we took a critical realist approach which recognises that participants' accounts are influenced by their social setting but nevertheless can be used to gain insight into their beliefs and experiences.

\section{Results}

Participants' discussions included every stage of the retrofit energy efficiency programme from securing funding through to measuring performance. Four distinct themes were identified which are described below and illustrated with quotes from the focus groups. These themes are also illustrated in Figure 1. Throughout the paper we use the term "participants" to mean those from all the different professional groups. Where the results are particularly relevant to a particular professional group this is noted in the text. 


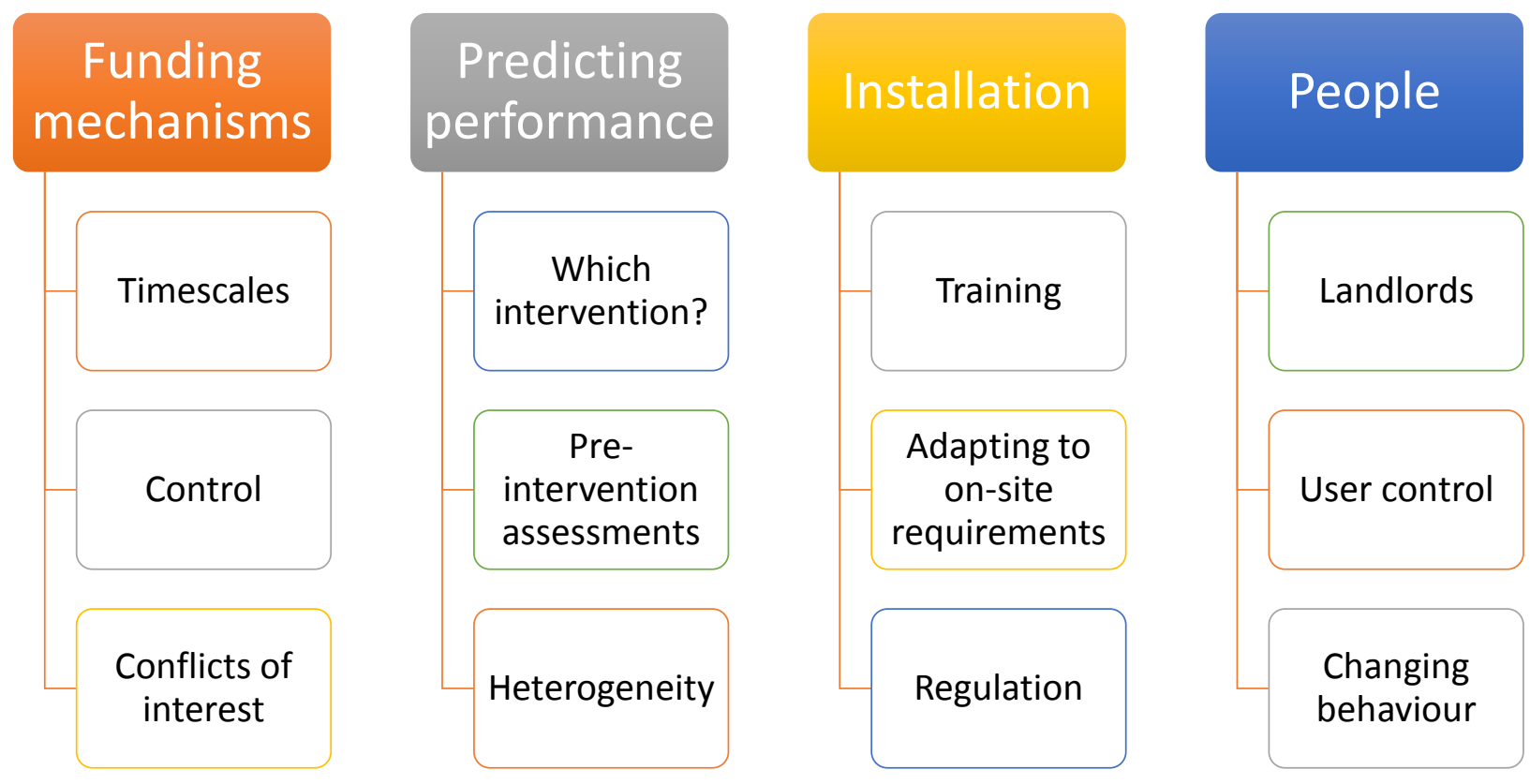

Figure 1: Thematic map of retrofit challenges

\subsection{Funding mechanisms}

This theme is about how funding mechanisms to support energy efficiency can introduce operational problems around planning and commissioning programmes. There are three sub-themes: timescales; the need for more control; and conflicts of interest.

\section{Timescales}

Participants discussed how funding mechanisms can make it more difficult to plan, carry out and evaluate programmes of work. This was particularly relevant for the local authority housing and policy officers, the housing association officers, the Green Deal providers and contractors, and the university researchers. They highlighted how funding streams are often volatile and require local authorities and housing associations to move quickly in order to secure funding. More time would enable them to take a more considered approach to the programme, including identifying which homes to include, which interventions to commission, and how best to communicate with residents and landlords. They also wanted funding mechanisms that continue in the longer term, and they highlighted how commitment to a funding programme should transcend political change. Housing association officers and 
local authority housing and policy officers described how the level of funding available can vary, which adds to their difficulties when planning a scheme. For example, when the timeframe of funding means they need to start a scheme while there are still uncertainties about pricing, it is very difficult to communicate with residents about what would be involved. Local authority and social housing and policy officers described how getting residents to make any financial contribution at all to energy efficiency improvements can be challenging and this is exacerbated when they are being asked to agree to a programme of works before they know the exact amount they need to pay. They also highlighted the difficulties that arise when a funding stream changes mid-programme and so the contribution residents are expected to make can change too. Because residents talk to their neighbours about the scheme, any inequities in subsidies and contributions quickly become apparent and cause dissatisfaction and distrust. They talked about the need for a long-term approach to funding schemes that enables them to properly plan and carry out programmes. All participants talked about how they would like to monitor energy efficiency performance in a sample of homes, which requires collecting data over a period of time, including the heating period before the installation. However, the timescales they need to work to in order to meet funding requirements means it is often impossible to obtain sufficiently long pre-installation data to allow performance to be evaluated.

“Energy efficiency should be an infrastructure programme, like HS2” (FG3)

"People can't understand why they pay different amounts to their neighbours." (FG5)

\section{Control}

Many participants, particularly those who worked in local authorities and housing associations, talked about how they would like greater control over the budget they have for energy efficiency retrofit schemes. This would enable them to tailor programmes to meet the needs of specific developments. They highlighted that they would like to allocate funding to support improvements to a whole area, rather than having to consider eligibility for funding on a home-by-home basis. They talked about how the funding available for private homes and local authority homes can be different, even when the homes are on the same development. This can cause problems, particularly in areas that have a mix of tenure. It can lead to some homes receiving energy-efficiency improvements while neighbouring properties do not.

"Funding should be tenure-blind and enable an area-by-area approach." (FG3) 
Local authority and housing association officers talked about how policies can result in funding being made available for specific improvements, and that these improvement programmes tend to operate in isolation. This could be due to constraints in the funding scheme itself or because a variety of funding schemes are used for different retrofit programmes and the different programme managers are operating in isolation. They would prefer a situation in which they could consider the needs of the entire home, or link different programmes of work. For example, they discussed how there might be a programme for replacement boilers, which would require the boiler flue in a dwelling to be replaced, yet a few months later the same dwelling has external wall insulation installed, which means that the new flue needs to be replaced again. The new boiler may also be over-sized for the lower-heat loss retrofitted dwelling. It would be better if the two programmes were linked, so that when the boiler is replaced an appropriate model is selected and a longer flue is installed, suitable for the forthcoming external wall insulation. All participants talked about how the improvements that each home receives should be tailored to the needs of that home. For example, funding might be available for external wall insulation, yet a property's windows might need replacing, and doing so would make a bigger difference to its energy efficiency. They highlighted, however, that a whole-house approach would require individual surveys for each home and that there is a cost associated with this.

"The package has to be right for the property." (FG2)

\section{Conflicts of interest}

Participants discussed how the funding mechanism, via the Energy Company Obligation (ECO) can lead to a conflict of interest, often because much of the building stock in Leeds, and especially the homes they work with, is considered hard to treat. Energy suppliers have their own targets to meet, which may be better served by interventions in larger more affluent households. Participants suggested that there should be a policy implemented which means that ECO price requirements don't compromise the quality of installations. They suggested that funding mechanisms should change so that decision-making responsibility is removed from energy companies.

All participant groups highlighted that many people want to make their homes more energy efficient but do not want to take out a loan. Residents can perceive a conflict of interest between trying to save money by installing insulation and being charged interest on a loan, albeit at low interest rates. This means that the Green Deal scheme appears unattractive. However, some participants, particularly the Green Deal providers and contractors described 
how residents might have a Green Deal assessment and then decide to pay for their improvements themselves rather than take out a loan with the energy companies. Hence while uptake of the Green Deal is low, the awareness it generates is greater than might be assumed.

Some participants, particularly the environmental designers and local authority housing and policy officers, also talked about how there can be a conflict of interest between different local authority departments, for example between housing and planning officers when there are challenges over the need for external wall insulation requiring a planning application. Some of these participants suggested that manufactures should be more involved in finding a solution to planning permission problems. All participant groups talked about the need for manufacturers to continue to innovate, and they discussed how important it is that manufacturers are encouraged to continue investing in research and development programmes, even though it may be easier for them to concentrate on established products.

“Energy companies are taking financial short cuts. They're creating a barrier to real sustainable markets." (FG1)

\subsection{Predicting performance}

This theme is about the importance of and difficulties in predicting how retrofitting energy efficiency improvements will change a home's energy performance and about how a home's fabric presents challenges for energy improvement schemes. There are three sub-themes: which intervention?; pre-intervention assessments; and heterogeneity.

\section{Which intervention?}

Participants discussed how one of the biggest problems they face is knowing which interventions make the biggest difference for a particular property type. This was particularly relevant for local authority housing and policy officers and housing association officers. This means that they can lack confidence in deciding which type of intervention a retrofit scheme should focus on, particularly for hard-to-treat homes. They discussed how there are uncertainties over the long-term implications of moisture levels in walls and timbers, for example from internal wall insulation, but for some homes this might appear to be the optimal solution. University researchers discussed how thermal bridging could lead to condensation, resulting in moisture in timbers and walls and in surface mould growth. Some participants (primarily housing and policy officers) talked about how it is possible to measure the water content of walls before an installation but they are not certain how the 
measurement should affect the intervention they choose. Both the potential for thermal bridging and pre-existing moisture levels are likely to make an installation more complex and participants discussed how there is often neither the time nor the budget available to put measures into place to avoid future problems. This lack of certainty over long-term adverse outcomes further increases their lack of confidence over which intervention to select, if any.

"We need to know about the long-term implications of moisture levels in walls, timber, dew points, etc." (FG6)

Some participants (primarily university researchers and environmental designers) talked about the difficulties that might occur when neighbouring homes are not treated, and concerns about the potential unintended consequences for both the treated and untreated homes. For example, insulating one home could make neighbouring properties worse since the amount of heat traveling between party walls may be affected by internal wall insulation returns. All participant groups highlighted how when any new technology is introduced there is a period of learning, both in terms of the product itself and its optimal use.

"The challenge is having confidence in knowing exactly which measures can make the biggest difference. What should we be focusing on?" (FG3)

\section{Pre-intervention assessments}

Participants talked about how problems with the pre-intervention assessments can exacerbate the task of predicting performance. For example, the extent to which the property is air tight has a large effect on its energy efficiency, yet it is not easily included in RdSAP and it does not usually form part of a property survey, even though it could be critical in considering which measure to install and what the payback times might be. A further problem identified was the Green Deal energy assessments. Participants discussed how they can be inaccurate and some highlighted that because the Green Deal assessment is non-invasive it inevitably lacks accuracy. Others described how assessors make mistakes, both on the energy assessment and the occupancy assessment and that there are insufficient quality checks in place. They suggested a small sample of homes should have the assessment independently checked, although they discussed the difficulties associated with funding a system of quality checks. Some suggested that requiring assessors to submit photographic evidence to accompany the assessment might increase quality. Overall participants discussed how the Green Deal assessment is of limited value when reaching decisions about the optimal energy efficiency improvements that an individual home would 
benefit from, and they believed that it is an inadequate basis for determining a substantial programme of work.

"Mistakes are made on the Green Deal assessments and there should be a system of checks put in place, for example 5\% should be checked. At the moment it's an inadequate basis for a programme of works." (FG4)

\section{Heterogeneity}

Participants discussed how predicting the performance of energy efficiency measures is particularly difficult for individual houses as different houses on the same street will perform differently. While they discussed how this is partly due to differences in occupant behaviour, some participants (primarily the university researchers) highlighted that other factors have a major impact on efficiency, including orientation, which can affect the amount of solar flux, and repair and maintenance history, which can affect the moisture levels or the air paths between the conditioned and unconditioned spaces. Alterations and extensions can introduce or change junctions vulnerable to both thermal bridging and breaches of airtightness whilst different treatment of draughts or designed ventilation can influence surface or interstitial condensation levels, all of which contribute to differing thermal performance.

"Even properties of the same type on the same street will perform in different ways. It's not standard as often assumed." (FG6)

In addition, they discussed how there are uncertainties over the long-term implications of moisture levels in walls and timbers, for example from internal wall insulation. They talked about how different homes can have different levels of insulation already installed, and this further adds to their lack of confidence in performance. Some participants (university researchers, environmental designers and housing, policy and project officers) talked about how thermal bridging can lead to increases in condensation and that the extent of thermal bridging is different in individual homes.

Overall participants highlighted the need to better understand the performance gap and to use this understanding to provide more accurate individual assessments for properties. They discussed that this might require larger datasets than are typically available to them. Participants talked about how the best way of overcoming this challenge is for stakeholders to share performance data in an accessible and engaging format. These stakeholders include manufacturers, contractors and housing providers and sharing data would require 
both successes and failures to be disclosed. Housing and provider participants in particular discussed how it is important to ensure that performance data is presented simply and without technical jargon so that they can understand it and therefore use it to inform their practice.

\subsection{Installation}

This theme is about the problems associated with installing energy efficiency measures, most commonly external wall insulation. There are three sub-themes: training; adapting to on-site requirements; and regulation.

\section{Training}

During discussions participants (particularly providers and contractors) talked about the problems associated with training installers, especially on the details of external wall insulation installation. Some participants talked about how PAS 2030 is not sufficiently stringent and results in installers who, despite being accredited, do not have a detailed knowledge of why installations are done in specific ways. They talked about how tightening PAS 2030 would raise the standards for installation. Some participants suggested that it would be useful to develop a pre-installation training package for installers based on what has been learnt from previous programmes. They talked about how thermal bridging and air quality measures, along with pre- and post-installation thermal imaging could be used as part of a training session to help installers understand how small details can make a big difference to performance. Participants discussed how, despite wanting manufacturers to make things simple, they also wanted manufacturers to continue to innovate. The challenge, therefore, is how to keep installers updated with new products.

"There should be a tighter version of PAS 2030. You should have to demonstrate knowledge of the detail." (FG3)

\section{Adapting to on-site requirements}

Participants, particularly contractors and housing officers, discussed how installers often have to find ways of overcoming challenges they face on site. Often these are caused by external wall insulation system designers not providing sufficient detail for individual properties, for example how to deal with built-in storage areas for bins that form part of the existing properties. Installers therefore have to make decisions and adapt the design on-site, which can lead to difficulties. For instance, adding external wall insulation to a bin storage 
area would mean that it would no longer be large enough to house the bins, which residents would be unhappy about, yet leaving that part of the wall uninsulated reduces effectiveness, allows thermal bypassing, and leads to thermal bridging, which introduces the potential for moisture-related problems. Contractors also highlighted that they face difficulties when working around utility cables and equipment, and that utility companies can take a long time to respond to requests for equipment to be moved. They highlighted that it might take legislation to ensure that these bodies act quickly enough so that work on site isn't compromised or delayed. Participants discussed how these sorts of on-site difficulties and decisions can result in potential energy efficiency performance problems. Participants talked about how it would be useful for manufacturers to develop easy-to-install pre-fabricated insulation elements, for example factory-built pre-insulated dormer pods to fit on the roof on back-to-back terraces which would alleviate a lot of the problem.

"The system design has got to show enough detail so the installers don't have to make it up on site." (FG3)

"Telecom and all the other utilities should have to move their cables within a set time." (FG5)

\section{Regulation}

Some participants, particularly local authority and housing association officers and university researchers, talked about how there can be a lack of on-site quality control to ensure the quality of works in progress. They highlighted that there should be a process for inspecting works right the way through the installation process rather than simply at the end. This inspection should go beyond the quality of finish. This might identify performance problems at a stage when they can be rectified. Some participants suggested that there should be greater emphasis on quality control, and some that inspections should be the responsibility of a separate independent body: the "retrofit police". Performance should also be part of the post-installation checks and installers should be required to return and rectify any problems identified.

"There should be a separate body to undertake checks throughout the installation process." (FG3)

"Contractors can focus on what looks good rather than making sure things are done properly." (FG5) 
"All too often 'build quality' is misinterpreted as 'quality of finish'. They are two very different things." (FG6)

\subsection{People}

This theme is about the challenges associated with dealing with landlords and occupants, including uncertainty about how occupier behaviour can affect energy use and how to change behaviour. There are three themes: landlords; user control; and changing behaviour.

\section{Landlords}

Local authority housing officers discussed how there are additional challenges to overcome for rented properties. They talked about how private landlords can be difficult to identify and contact, and how they can be reluctant to engage with programmes. Landlords can believe that retrofit programmes are not in their best interests, particularly when they are required to make a financial contribution: their tenants pay the bills and so it is the tenants who benefit from insulation. To overcome this, participants talked about the need to develop a clear specification of the works that would be done that details the objectives, requirements, timescales and the benefits to landlords. Some participants discussed how new legislation could be introduced to encourage landlords to engage with retrofit schemes. They suggested introducing a thermal performance tax for private landlords, which would provide immediate benefits of improving the energy efficiency of the homes they rent out.

"Private landlords aren't interested, it's not in their interests. Tenants sometimes want the scheme and landlords can jeopardise this." (FG1)

\section{User control}

One challenge to predicting energy savings that participants identified was the variability in the ways in which residents' heat and use their homes. Participants highlighted that there is tremendous variation in residents' beliefs about what constitutes a comfortable temperature, and accordingly, variation in the temperature to which they heat their homes. There is also variability in how residents control the temperature of their homes. Participants, in particular university researchers and housing officers, discussed how residents are often unsure about how to operate the temperature controls in their home and how this can mean that homes are heated inefficiently. They discussed that the range of methods that are used to control the temperature within homes makes it difficult to educate residents on energy efficiency. All groups of participants suggested that following any works there should be a handover to the 
residents which addresses how to control the temperature, such as using thermostatic radiator valves and programming the central heating.

"All the different types of heating controls makes it difficult to educate residents." (FG2)

\section{Changing behaviour}

Participants discussed the need to raise general awareness of the importance of energy efficiency. They believed that this would make it easier to engage with both landlords and residents and that it would increase the uptake of schemes. Some participants talked about how behaviour change is fundamental to the success of energy efficiency schemes and how it is insufficient to rely solely on increasing the efficiency of properties: the residents also need to become more energy efficient. Some participants believed that a separate funding scheme should be available for behaviour change interventions, and some discussed that the government has a duty to address behaviour. They suggested national information campaigns to raise awareness of the importance of energy efficiency. Some suggested embedding the importance of energy efficiency into the storyline of popular television programmes such as soap operas.

"Make energy efficiency normal." (FG3)

\section{Discussion}

We have explored the challenges that stakeholders in different roles face when implementing energy efficiency retrofit programmes. There are clearly frustrations around perceived barriers to delivering high-quality tailored energy efficiency solutions for individual homes. These include the funding mechanisms for retrofit programmes, uncertainties over which interventions will be most effective, the installation process, and how the behaviour of landlords and occupiers can impact on the success of the programme.

The funding mechanism for retrofit schemes was a clear source of frustration for many participants, and they talked about how the timescales place on many funding schemes means they have insufficient time to plan, publicise and implement a scheme. The timescales with which schemes need to be delivered can also make it impossible to collect sufficient high-quality data to allow a comparison of pre- and post-retrofit performance. An absence of sufficient pre-retrofit data has been noted elsewhere (e.g. Gupta et al., 2015). This lack of quality data, and therefore robust conclusions about the performance gap and how to minimise it, can lead to people responsible for commissioning retrofit schemes being 
uncertain about which interventions are best suited to which type of hard-to-treat property. There was a desire for greater collection and sharing of evaluation data. Participants were mindful that open access to outcome evaluation data would involve housing associations, local authorities, government departments and manufacturers co-operating and sharing negative as well as positive findings. However, this would provide commissioners with much more confidence when managing retrofit programmes for hard-to-treat homes.

Participants also highlighted problems with the quality of installation. Previous research has attributed installation-related problems to products being substituted or mistakes being made on site (e.g. Gupta et al., 2015). Our research has shown that many of the performance problems arise from site workers having to make decisions about how insulation should be applied because the designer did not provide sufficient detail, or having to adapt a design due to practical problems in implementing it. Improving the quality of a retrofit installation therefore requires the system designer to conduct more thorough site surveys before specifying a design and providing greater detail of how to overcome practical difficulties in installing insulation. Difficulties could also be detected during post-installation quality surveys. However, participants acknowledged that a planner or policy officer's priority is often to commission the work within the required timeframe rather than quality control and that holding contractors to account is not a priority. Previous research indicates that most Green Deal suppliers believe that PAS 2030 standards are fit for purpose, although installers believe that there should be greater checks to ensure that the standards are followed (DECC, 2014). Our research shows there is much more cynicism about the extent to which PAS 2030 ensures installation standards are sufficiently high.

Participants were keen that the lessons learned from the Green Deal evaluation could help them to avoid serious post-installation problems and their unintended consequences in the future. For example, participants were conscious of the need not to cause damp and their concern was motivated by wanting to increase housing quality and not to introduce problems for residents. Problems with the quality of Green Deal assessments were commonly raised. Indeed, there are many inexperienced assessors, with one study showing that half the sample of assessors had conducted 20 or fewer Green Deal assessments (DECC, 2014). This might underpin some of the problems with the quality of assessments, although not the range of measures included in assessments. Participants discussed how assessments should be subject to quality checks, and while SAP-accredited organisations are required to have a quality control process, it was not clear whether participants were unaware of this or whether they believed the current regime does not go far enough. 
The research has also identified a perceived need for greater flexibility in the energy efficiency measures that are installed in individual homes. Participants were aware that a standardised approach to retrofitting a development is not ideal as it does not take into account the individual needs of the occupants but they did not go as far as suggesting occupants should be involved in decisions around which retrofit measures are installed, shown to be more effective (Vlasova and Gram-Hanssen, 2014). Sovacool (2014) highlights the question of the point at which projects become so large that the benefits arising from economies of scale are outweighed by the challenges associated with running a large-scale programme. The current research shows that the lack of flexibility associated with even small-scale retrofit schemes - involving dozens rather than hundreds of homes - mean that the most appropriate energy efficient measures are not always installed into individual homes, or the order in which improvements are made is sub-optimal. While it would be difficult to tailor large-scale retrofit programmes to meet the needs of individual families, it would be useful to first gain an overview of how occupants use their homes and to explain the purpose of the retrofit couched in everyday practices. Our research shows that stakeholders are aware of the rebound effect - i.e. thermal comfort taking (Sorrell et al., 2009) - but the prebound effect (Sunnika-Blank and Galvin, 2012) was not discussed. The prebound effect would mean that residents do not take advantage of the increased energy efficiency of their homes and continue to heat them to a temperature lower than they find comfortable. Participants' suggestions of having a resident handover would help counter the prebound effect. This needs to be a carefully planned and implemented programme as occupant handovers can be inadequate, leaving people confused about their retrofit (Brown et al., 2014). Participants also suggested incorporating a behaviour change intervention in retrofit programmes, and indeed, new funding schemes have been introduced in the UK to address energy behaviour change alongside retrofit schemes.

Although program components and their resulting issues are often context-specific many of the findings in the current study are generalizable beyond the UK. For example, when discussing the fluctuations in funding for the US Department of Energy's Weatherization Assistance Program (WAP), Harak (2012) concluded that a lack of consistent federal funding makes it difficult to retain contractors willing to deliver high-quality services to low-income clients. Moreover, installation issues have been identified as crucial for the success of on-bill financing of energy efficiency improvements in the United States (American Council of an Energy Efficiency Economy, 2012). Many on-bill programmes partner with Building Performance Institute (BPI) certified contractors to ensure quality for energy audits. Some municipalities, but not all, require a post-installation audit to ensure that the work was completed to a sufficiently high quality. Finally, an integrated utility service model has been 
advanced as the wave of the future and is currently being piloted in Fort Collins, Colorado. The integrated service model requires contractors to be able to holistically assess homes and make integrated recommendations to customers rather than individual retrofits being delivered separately (Rocky Mountain Institute, 2015). Thus, although the current study is UK-based, the findings are relevant to energy efficiency programme implementation broadly.

\section{Strengths and limitations}

As far as we are aware, this is one of the first participatory action research projects looking at the implementation of various energy efficiency policies. The strength of this approach is the ability to explore policies from multiple perspectives and in this way to gain insight into how the same policies are played out in different organisations and environments. The focus group approach enables in-depth insight to be gained through dynamic exchanges within the groups. Discussions are focused around the topic of interest but not constrained to a series of closed questions in the way that a survey would be. While the qualitative approach means that the results obtained are more grounded in participants' experiences, the smaller number of participants involved means that it is more difficult to generalise the results. Running the project alongside a learning event meant that it was possible to attract participants from a wide range of roles and organisation. However, there are some limitations. Participants were those interested in the monitoring project and so may not be fully representative. Contractors were under-represented and so not every group had a participant with experience of installing retrofits so that these groups may have discussed the problems with installation more than the challenges installers face. Likewise, local authority planners and private landlords were not represented. Neither were occupants themselves. Because the day included presentations of the monitoring results, there may have been a bias towards the importance of monitoring and evaluation or a focus on the importance of the topics covered during the presentations. For example, the results of hygrothermal simulations were presented that indicated that the level of insulation specified may have a detrimental effect on any existing timber present in a solid walls. This may have increased participants' concerns about potential adverse outcomes from retrofit programmes. Finally, because most of the properties had been fitted with internal or external wall insulation, the discussions concentrated on this specific retrofit approach to energy efficiency. Nevertheless, the research findings around funding mechanisms, selecting an intervention and dealing with people are relevant to a range of different technologies. 


\section{Conclusions and Policy Implications}

We used a participatory action research approach to explore the various challenges presented by domestic energy efficiency retrofit schemes. Our research leads to the following conclusions.

- Commissioners of retrofit programmes should have greater control of the budget and a longer time period to implement programmes, enabling better planning, communication and allowing greater integration of different interventions. This would also allow thorough before-and-after monitoring of energy efficiency and occupant behaviour.

- A brief guide to the range of interventions and their indications and contraindications should be developed for commissioners which will give them more confidence that they are selecting the most appropriate intervention for dwellings. A flowchart to guide them in their decisions, together with a checklist of assessments that need to be done before installation (e.g. additional roof insulation) that would minimise potential post-installation problems would be useful.

- Better sharing of performance data would result in greater confidence in selecting the best intervention for individual developments.

- There is a need for better surveying tools and measurement methods used in preintervention assessments. The current the dependency on rdSAP as the only means to validate and quantify energy efficiency improvements should be removed.

- Commissioners should have greater freedom to determine the most appropriate intervention for individual homes within a funding programme, rather than the programme only supporting one technology.

- Energy efficiency support should be provided for residents to help them better understand how to control the temperature in their homes effectively and the steps they can take to reduce the energy they use.

- Installers should have better training and more ongoing quality checks during and after installation. A policy on who will meet the costs of quality checks and better trained installers and enforced standards is required. So that programmes don't try to shift the 
blame onto residents if energy savings aren't as predicted there should be an energy performance assessment in every development.

\section{References}

American Council for an Energy Efficiency Economy (2012). On-bill financing for energy efficiency improvements. Washington DC: American Council for an Energy-Efficient Economy. Available from: http://aceee.org/files/pdf/toolkit/OBF toolkit.pdf [Accessed: 27th June 2016].

Boardman, B. (2007) Home Truths: A Low Carbon Strategy to Reduce UK Housing Emissions by $80 \%$ by 2050 . ECI Research Report 34. Oxford, University of Oxford Environmental Change Institute.

Braun, V., \& Clarke, V. (2006). Using thematic analysis in psychology. Qualitative Research in Psychology, (2): 77-101.

BRE. (2008) Energy Analysis Process Report - A study of hard to treat homes using the English House Condition Survey. Part 1: Dwelling and Household Characteristics of Hard to Treat Homes. Prepared by BRE Housing, with the support of DEFRA and Energy Savings Trust. Crown copyright 2008.

Brown, P., Swan, W., \& Chahal, S. (2014) Retrofitting social housing: reflections by tenants on adopting and living with retrofit technology. Energy Efficiency, 7: 641-653.

Carbon Trust (2011) Closing the Gap: Lessons Learned on Realising the Potential of Low Carbon Building Design. Report CTG047. London: Carbon Trust.

Climate Change Act 2008: Chapter 27. London: The Stationery Office. Available from: http://www.legislation.gov.uk/ukpga/2008/27/pdfs/ukpga 20080027 en.pdf [Accessed: $2^{\text {nd }}$ November 2015].

Committee on Climate Change (2008) Building a Low-Carbon Economy - The UK's Contribution to Tackling Climate Change. London: The Stationery Office. Available from: http://archive.theccc.org.uk/aws3/TSO-ClimateChange.pdf [Accessed: $2^{\text {nd }}$ November 2015].

Cronin de Chavez, A., Tod, A., Homer, C., Nelson, P., Stocks, A., \& Powell-Hoyland, V. (2014) Warm Well Families: Rotherham Final Report. Available from: http://shura.shu.ac.uk/7906/1/Rotherham Final Report March 2014.pdf [Accessed: $12^{\text {th }}$ June 2015].

DCLG. (2012). English housing survey 2012: energy efficiency of English housing report. London: Department for Communities and Local Government. Available from: https://www.gov.uk/government/uploads/system/uploads/attachment data/file/335756/EHS Energy efficiency of English housing 2012.pdf [Accessed: $2^{\text {nd }}$ November 2015]. 
DECC (2012) National Energy Efficiency Data-Framework. Summary of analysis using the National Energy Efficiency Data-Framework. London: DECC. Available from https://www.gov.uk/government/uploads/system/uploads/attachment_data/file/65969/6861 need-report-nov-2012.pdf. [Accessed $2^{\text {nd }}$ November 2015]

DECC (2013) Local Authorities and the Green Deal [Online]. Accessed $2^{\text {nd }}$ November 2015. Available at: https://www.gov.uk/guidance/local-authorities-and-the-green-deal).

DECC (2014) Research into the Green Deal and ECO Programme Supply Chain. Available from:

https://www.gov.uk/government/uploads/system/uploads/attachment data/file/421010/P10 GD Supply chain research.pdf

DECC (2015) Annual Fuel Poverty Statistics Report, 2015. London: Department for Energy and Climate Change. Available from:

https://www.gov.uk/government/uploads/system/uploads/attachment data/file/468011/Fuel Poverty Report 2015.pdf [Accessed: $2^{\text {nd }}$ November 2015].

Department of Energy Weatherization Assistance Program, Available from http://www.energy.gov/eere/wipo/weatherization-assistance-program [Accessed 21st June 2016]

Electricity and Gas (Energy Companies Obligation) Order, 2012. London: The Stationery Office. Available from:

http://www.legislation.gov.uk/ukdsi/2012/9780111530276/pdfs/ukdsi 9780111530276 en.pd f [Accessed $9^{\text {th }}$ November 2015]

Energy Efficiency (Private Rented Property) (England and Wales) Regulations 2015. Available from: http://www.legislation.gov.uk/uksi/2015/962/pdfs/uksi 20150962 en.pdf [Accessed $4^{\text {th }}$ November 2015.

EST. (2004). Hard to Treat Homes Guide. London: Energy Savings Trust.

Fuel Poverty (England) Regulations, 2014. London: Her Majesty's Stationery Office. http://www.legislation.gov.uk/ukdsi/2014/9780111122198/pdfs/ukdsi 9780111122198 en.pd f [Accessed $9^{\text {th }}$ November 2015]

Galvin, R. (2014) Why German owners are reluctant to retrofit. Building Research and Information, 43: 435-451.

Gupta, R., Gregg, M., Passmore, S. and Stevens, G. (2015) Intent and outcomes from the Retrofit for the Future programme: key lessons. Building Research and Information, 43: 398408.

Harak, C. (2012). National low-income weatherization: Stimulus-funded program shines but storm clouds are on the horizon. Boston: National Consumer Law Center. Available from https://www.nclc.org/images/pdf/energy utility telecom/weatherization/weatherize-report.pdf [Accessed: 27th June 2016].

House of Commons Energy and Climate Change Committee (2013) The Green Deal: 
watching brief, Volume 1. First Report of Session 2013-14. London: The Stationery Office. Available at:

http://www.publications.parliament.uk/pa/cm201314/cmselect/cmenergy/142/142.pdf [Accessed 30 ${ }^{\text {th }}$ October 2015]

Isaksson, C. (204) Learning for lower energy consumption. International Journal of Consumer Studies,38: 12-17.

Johnston, D. Farmer, D. Brooke-Peat, M. and Miles-Shenton, D. (2014) Bridging the Domestic Building Fabric Performance Gap. Building Research \& Information. Published online version on 3rd December 2014. DOI:10.1080/09613218.2014.979093.).

Johnston, D. Lowe, R. and Bell, M. (2005) An Exploration of the Technical Feasibility of Achieving $\mathrm{CO}_{2}$ Emission Reductions in Excess of $60 \%$ Within the UK Housing Stock by the Year 2050. Energy Policy, Vol. 33 (13), pp.1643-1659.

Johnston, D. Miles-Shenton, D. and Farmer, D. (2015) Quantifying the Domestic Building Fabric ‘Performance Gap'. Building Services Engineering Research \& Technology, 36: 614627. DOI:10.1177/014362441557034.

Killip, G. (2008) Building a Greener Britain: Transforming the UK's Existing Housing Stock. A Report for the Federation of Master Builders by the University of Oxford Environmental Change Institute. London, Federation of Master Builders.

Linden, A. L., Carlsson-Kanyama, A., Eriksson, B. (2006) Efficient and inefficient aspects of residential energy behaviour: what are the policy instruments for change? Energy Policy, 34: 1918-1927.

Lowe, R., \& Oreszczyn, T. (2008) Regulatory standards and barriers to improved performance for housing. Energy Policy, 36: 4475-4481.

Marmot Review Team (2011) The health impacts of cold homes and fuel poverty. London: Friends of the Earth.

Preston, I. White, V. Thumim, J. Bridgeman, T. Brand, C. (2013) Distribution of Carbon Emissions in the UK: Implications for Domestic Energy Policy. A Report produced by the Centre for Sustainable Energy. York: Joseph Rowntree Foundation.

Public Health England (2014) The Cold Weather Plan for England 2014. Protecting health and reducing harm from cold weather. London: Department of Health.

Rocky Mountain Institute (2014). Integrated utility services: A new business model for Fort Collins Utilities. Colorado: Rocky Mountain Institute. Available from http://www.rmi.org/Knowledge-Center/Library/2014-36_eLabFortCollinsIUS+Report-FINAL20141219 [Accessed: 27th June 2016].

Rosenow, J., Platt, R. and Flanagan, B. (2013) Fuel poverty and energy efficiency obligations - A critical assessment of the supplier obligations in the UK. Energy Policy, 62:1194- 1203 .

Skea, J. (2012) Research and evidence needs for decarbonisation in the built environment: a UK case study. Building Research \& Information, 40: 432-445. 
Sorrell, S., Dimitropoulos, L., and Sommerville, M. (2009) Empirical estimates of the direct rebound effect: A review. Energy Policy, 37: 1356-1371.

Sovacool, B. (2014) What are we doing here? Analyzing fifteen years of energy scholarship and proposing a social science research agenda. Energy Research and Social Science, 1: $1-14$.

Stafford A. Bell, M. and Gorse, C. (2012) Building Confidence - A Working Paper. Centre for Low Carbon Futures Report No. 008, March 2012 [Internet]. York, The Centre for Low Carbon Futures. Available from: http://www.lowcarbonfutures.org/reports/researchreports? page $=1$ [Accessed: $2^{\text {nd }}$ November 2015].

Summerfield, A.J. and Lowe, R. (2012) Challenges and future directions for energy and buildings research. Building Research \& Information, 40: 391-400.n

Sunikka-Blank, M., Chen, J., Britnell, J., and Dantsiou, D. (2012) Improving energy efficiency of social housing areas: a case study of a retrofit achieving an "A" energy performance ratings in the UK. European Planning Studies. 20: 131-145.

Sunikka-Blank, M., and Galvin, R. (2012) Introducing the prebound effect: the gap between performance and actual energy consumption. Building Research \& Information, 40: 260-273. Walter, M. (2009) Participatory action research. In: Walters M, editor. Social Research Methods. 2nd ed. Oxford: Oxford University Press.

Vlasova, L., and Gram-Hanssen, K. (2014) Incorporating inhabitants' everyday practices into domestic retrofits. Building Research \& Information, 42: 512-524.

Warm Homes and Energy Conservation Act (2000). Available from:

http://www.legislation.gov.uk/ukpga/2000/31/pdfs/ukpga 20000031 en.pdf $\left[\right.$ Accessed $9^{\text {th }}$ November 2015] 